\title{
O ENSINO DE PERÍFRASES VERBAIS E VERBO-NOMINAIS
}

\author{
Vinicius Maciel de OLIVEIRA \\ Universidade do Estado do Rio de Janeiro - Faculdade de Formação de Professores \\ vmoliveira@me.com \\ Giselle Aparecida Toledo ESTEVES \\ Universidade Federal do Rio de Janeiro \\ giselle esteves@hotmail.com
}

Resumo: Neste artigo, discutimos o ensino de perífrases verbais e verbonominais, com base na análise de gramáticas tradicionais, descritivas, materiais pedagógicos entre outros estudos em âmbito acadêmico, fundamentando nossas ideias na proposta de que os usos moldam constantemente o sistema linguístico; isto é, este trabalho ancora-se na perspectiva funcionalista. Pretendemos responder às seguintes questões: (i) como as gramáticas tradicionais e alguns estudos linguísticos recentes abordam o uso de perífrases verbais e de estruturas com verbos-suporte? e (ii) quais atividades com estas construções são bastante recorrentes em livros/textos didáticos? A partir da reflexão sobre o uso e a abordagem de perífrases verbais e verbo-nominais, propomos algumas alternativas para 0 trabalho com o tema levantado que estejam adequadas às orientações dos Parâmetros Curriculares Nacionais. Nossa proposta visa a analisar aspectos da forma e do significado das construções em foco, tentando demonstrar como os efeitos de significado podem ser explicados em função do gênero textual que integram. Em função dessa concepção de língua e do encaminhamento sugerido, acreditamos que, nas aulas de morfossintaxe, devem ser abordadas as noções de variação e mudança linguísticas e, com isso, espera-se que o aluno compreenda que a gramática não é um objeto estático e homogêneo, mas um organismo vivo de natureza, essencialmente, heterogênea.

Palavras-chave: Perífrase verbal. Verbo-suporte. Ensino. Gramática. Funcionalismo.

\section{THE TEACHING OF VERBAL AND VERB-NOMINAL CIRCUMLOCUTIONS}

Abstract: In this article, we discuss the teaching of verbal and verbal-nominal circumlocutions, based on the analysis of traditional grammars, descriptive grammars, teaching materials and other studies in academic, basing our ideas in the proposal that uses constantly shape the linguistic system; that is, this work is anchored in the functionalist perspective. We intend to answer the following questions: (i) how do the traditional grammars and some recent linguistic studies approach the use of verbal circumlocutions and structures with light verb? and (ii) what activities these constructions are quite recurrent in books / teaching materials? From the reflection on the use and approach of verbal and verb-nominalcircumlocutions, we propose some alternatives to work with the raised issue that are appropriate to the guidelines of the Parâmetros Curriculares Nacionais. Our proposal aims to analyze aspects of form and meaning of the constructions in focus, trying to demonstrate how the effects of

Artigo recebido em 07/02/2016 e aceito em 24/06/2016. 
meaning can be explained due to the genre that integrate. Because of this conception language and suggested referral, we believe that in the morphosyntax teaching, the variation and linguistic change notions must be approach and, therefore, it is expected that the student understands that the grammar is not a static object and homogeneous, but a living organism in nature, essentially heterogeneous.

Keywords: Verbal circumlocutions. Light verb. Teaching. Grammar. Functionalism.

\section{Introdução}

(...) Não diga em duas palavras o que você puder exprimir em uma. (...) mencionar substitui com vantagem fazer referência (...) (MARTINS FILHO, 1992, p. 73 (Grifo nosso)

Usar ou não construções complexas? Qual a posição de algumas gramáticas normativas? $O$ que revelam alguns estudos linguísticos sobre 0 assunto? A partir desses questionamentos, tencionamos apresentar entraves, avanços e algumas alternativas no que concerne à abordagem de perífrases verbais com "ir" ("vai chover", "vamos ver") e verbo-nominais com "dar" ("dar amor", "dar notícia”) em alguns materiais (livros didáticos, gramáticas normativas e um manual de redação). Nossa discussão baseia-se em pesquisas recentes realizadas sobre gramaticalização de verbos.

Acreditamos que, nas aulas de Língua Portuguesa, o trabalho acerca do funcionamento de certos elementos e estruturas linguísticos, especialmente relacionado à categorização verbal, na grande parte, gera desconfortos tanto da parte do professor como na do aluno. No primeiro, porque a obrigação contundente em ensinar a língua portuguesa das gramáticas e dos livros didáticos não permite, muitas vezes, a observação do verdadeiro comportamento da língua e de seus componentes. No segundo, porque não compreende a necessidade de certas nomenclaturas que Ihes são ensinadas sem que haja conexão com emprego efetivo dos termos aos quais se referem. Nesse sentido, temos um ensino com o sucesso comprometido, pois não colabora para a formação de cidadãos "participativos, reflexivos e autônomos" (PCN, 1998).

\section{Abordagem de perífrases verbais e verbo-nominais}




\subsection{Em algumas Gramáticas Tradicionais}

Ao tratarem de predicações verbo-nominais, Bechara (1999), Rocha Lima (1992, p. 250) e Cunha E Cintra (2001, p. 379) ignoram a função de núcleo semântico do elemento nominal (doravante, SN) em construções perifrásticas cujos nomes auxiliam o verbo a selecionar argumentos ("dar tiros", "dar pulos", "dar amor").

O item "dar", em Bechara (1999), não aparece em qualquer consideração do autor quanto à noção de verbo. Consequentemente, o leitor, tendo em vista as definições de categorias tratadas nessa obra, pode considerá-lo como "irregular" quanto à flexão e somente como "verbo" em construções com dar + SN (por exemplo: "dar um lápis" - "entregar um lápis", "dar origem” - "originar”, "dar medo" - "causar medo" ou "amedrontar").

No que concerne ao tratamento dos auxiliares, Bechara (1999) considera os verbos "ter", "haver", "ser"como os auxiliares que, juntamente com o particípio do verbo principal, formam os tempos compostos que, unidos aos simples, completam o quadro da conjugação da voz ativa. "Ser", "estar" e "ficar" combinam-se com um particípio passível de flexão em gênero e número do verbo principal para formar uma predicação na voz passiva. Há, ainda, os auxiliares acurativos (começar a / estar para / continuar + gerúndio / estar + gerúndio / ir + gerúndio / tornar a / acabar de), modais (dever / poder / querer / pretender / conseguir / parecer / ir / vir), causativos (deixar / mandar / fazer) e sensitivos (ver / ouvir / olhar / sentir).

Rocha Lima (1992, p. 250) faz menção às construções verbo + SNao tratá-las como "conglomerados" e ao afirmar que são construções "verbo + objeto direto" que "equivalem muitas vezes a verbos simples: ter medo (= temer), ter amor a (= amar), fazer guerra a (= guerrear), pôr freio a (= refrear), etc". Logo, não trata devidamente a existência de predicadores complexos formados por verbo + SN, pois não considera que este elemento, apesar de não ser um predicativo do sujeito, partilha com o verbo a função de núcleo da 
predicação, como em "A menina deu telefonemas para a mãe" ou em "Todos têm medo da violência".

Rocha Lima (1992, p. 134), ao arrolar os auxiliares, inclui "ir" ("a tarde ia morrendo"). Entretanto, assim como Cunha \& Cintra (2001), o autor não reconhece a estrutura ir + verbo principal como uma conjugação dentro de um paradigma, ou seja, Rocha Lima não concebe um futuro do presente composto. O autor afirma que "ter", "haver" e "ser" são os auxiliares fundamentais e formam os tempos compostos descritos nos paradigmas.

Cunha e Cintra (2001) definem apenas três tipos de verbos quanto à função: (i) verbo principal - "um verbo de significação plena, nuclear de uma oração" (Cunha \& Cintra, p. 387), (ii) verbos de ligação - "servem para estabelecer a união entre duas palavras ou expressões de caráter nominal (...) um elo entre este (o sujeito) e o predicativo" (Ibidem, p. 133), e (iii) verbo auxiliar - "desprovido total ou parcialmente da acepção própria, se junta a formas nominais de um verbo principal, constituindo com elas locuções que apresentam matizes significativos especiais." (Ibidem, p. 387). De acordo com essa classificação, o verbo "dar"nas construções do tipo dar+SN ("dar socos") teria de ser classificado como "verbo principal" e nas expressões do tipo "dar de cantar" ou "dar para viver" como "verbo auxiliar".

$\mathrm{Na}$ descrição dos verbos auxiliares, Cunha e Cintra (2001, p. 394-398) não consideram "ir" um auxiliar autêntico, e sim integrante de um grupo de verbos que podem, excepcionalmente, ser empregados como tal. Os autores comentam que "ir", acompanhado de uma forma no gerúndio, indica uma ação que se realiza "progressivamente ou por etapas" ("O navio ia encostandono cais" / "Os convidados iam chegandode automóvel"). Segundo os autores, a construção "ir + infinitivo" exprime "o firme propósito de executar a ação, ou a certeza de que será realizada em futuro próximo" (Vou procurarum médico / O navio vai partir). Embora Cunha e Cintra admitam o emprego de "ir" como auxiliar, nos paradigmas de conjugação, o futuro de presente do indicativo é representado apenas por formas simples (cantarei, venderei, partirei). Segundo os autores, a perífrase formada por "ir", flexionado no presente do indicativo, + infinitivo é uma substituta para a forma simples, mais adequada à língua falada 
(cf. p. 460-465). Ademais, os autores, não somente se referem à construção ir + infinitivo quando analisam o futuro do presente, como também ao tratar do modo imperativo (cf. p. 480). Demonstram que, em exemplos do tipo "Não vá se afogar, moço" e "Não vá me dizerque foi o Diabo", "ir" funciona como um reforço para que a noção de imperativo seja estabelecida.

\subsection{Em alguns estudos linguísticos e em algumas gramáticas de orientação descritiva}

Machado Vieira (2004) descreve "ir", conferindo-lhe duas extensões semântico-sintáticas: (i) verbo predicador(Ela vaiao cinema); (ii) verbo instrumental(Ela vai encontrar o namorado). A autora afirma que um verbo pode comportar-se como um predicador e/ou como instrumental, que, por sua vez, se subdivide em ligação, suporte e semi-auxiliar ou auxiliar. Essas categorias nada mais são do que um continuum de gramaticalizaçãoque tem no polo inicial os itens mais lexicais e no polo final os itens mais gramaticais.

A partir desse continuum, a autora estabeleceu cinco graus de afastamento do polo de auxiliaridade: (1) no primeiro grau, a autora engloba os verbos "ser", "estar" e "ficar", seguidos de particípio; (2) no segundo grau, insere "estar", "vir", "ir", "ficar" e andar, aspectuais em construções com verbo predicadorno gerúndio e "ir", "vir" e "haver (de)" temporais em construções com verbo predicadorno infinitivo; (3) no terceiro grau, "poder" e "dever" modais em construções com verbo predicadorno infinitivo e "estar", "ficar", "andar", "voltar", aspectuais (acurativos), seguidos da preposição "a" em construções com verbo predicadorno infinitivo; (4) no quarto grau, "ter (de)(que)" modal em construções com verbo predicadorno infinitivo e "estar", "ficar", "deixar" aspectuais seguidos de preposição "de", "para" ou "por" em construções com verbo predicadorno infinitivo; e (5) no quinto grau (mais próximo do polo lexical), "tentar", "querer", "esperar" seguidos de verbo predicadorno infinitivo, "mandar", "fazer", "deixar" e "levar" causativos em construções com verbo predicadorno infinitivo e "ver", "olhar", "ouvir", "sentir" perceptivos/sensitivos em construções com verbo predicadorno infinitivo. 
Quanto à caracterização dos verbos auxiliares, Mateus et al. (2003) apresentam alguns critérios de auxiliaridade que se resumem a seguir:

1) $O$ auxiliar não seleciona sintática nem semanticamente os argumentos, essa função fica por conta do verbo principal. ([0 menino] \{agente\}tem feitoos trabalhos.).

2) Se o aglomerado verbal for de fato uma perífrase, não será possível substituir o verbo principal por uma oração completiva introduzida por "que". ( ${ }^{\star} \mathrm{O}$ menino tem [que fez os trabalhos]).

3) Numa perífrase, só é possível utilizar um circunstanciador de tempo, pois só existe uma oração "um domínio temporalizado" (Mateus et al., 2003, p. 405). ( ${ }^{*}$ Hojeo menino tem feito os trabalhos ontem).

4) Construções perifrásticas admitem apenas uma negação à esquerda do auxiliar. Já em sentenças com dois verbos lexicais, a negação pode estar, também, à esquerda do segundo verbo. ( ${ }^{\star} O$ menino (não) tem nãofeito os trabalhos).

5) Se o complexo se tratar de uma perífrase, a colocação pronominal ocorrerá em adjacência ao primeiro verbo (em ênclise ou em próclise, a depender dos itens atratores). Se houver dois predicadores, os pronomes colocam-se, em geral, como clítico em relação ao segundo verbo, embora por vezes possam oscilar entre uma posição adjacente ao primeiro ou ao segundo. (O menino tem-nosfeito)

De acordo com as autoras, em construções do tipo ir + infinitivo, a forma verbal à esquerda apresenta uma categorização híbrida, sendo chamado de semiauxiliar. Essa definição baseia-se no fato de que "ir", nesse tipo de estrutura, não satisfaz a todos os critérios de auxiliaridade levantados pelas autoras. Segundo Mateus et al. (2003), o comportamento de "ir" é condizente aos seguintes critérios de auxiliaridade: impossibilidade de completiva finita, um só advérbio de tempo e uma só negação frásica (precedendo o auxiliar). Entretanto, não é aplicável ao critério que estipula a aproximação obrigatória do pronome clítico. (O professor vai corrigir os testes hoje / O professor vai corrigilos hoje). 
O estudo de Oliveira (2009) mostrou que "ir" é um verbo polifuncional e pode participar na construção de diversos tipos de predicações complexas: ir + infinitivo ("É... no começo das férias, aí então a minha tia vai escrever, então eu passo, aí depois a gente vai". - PEUL, Banco de Dados da Fala Infantil); ir + gerúndio ("Acabá com a violência. Eu acho que é o principal. Violência e as crianças na rua também que eu acho que é o principal. É: eu acho que tudo pode começá de tê tantas crianças na rua e com isso vão se marginalizando". PEUL, Amostra Censo); e ir + forma verbal flexionada ("Perto da minha casa. Aí vieram me falá que ele tava lá do outro lado do bloco, aí eu fui e atravesseiassim mesmo, e os tiro trocando pra lá e pra cá." - PEUL, Amostra Censo).

As análises qualitativas dos dados, segundo o autor, revelaram que 0 processo de gramaticalização de "ir" ainda não está acabado, pois há alguns contextos em que se constata um comportamento ambíguo, ocasionado, entre outros fatores, pela presença de um elemento locativo ("Aí eu atravessei a rua, fuinuma lanchonete comprámate pra eu tomá aqui no trabalho..." - PEUL, Amostra Censo / "ele vai, desliga... aí a gente vai lá e começa a pintáo carro". PEUL, Amostra Censo). Nesses exemplos, é possível reconhecer ainda a extensão semântica de movimento do verbo "ir"(deslocar-se para outro lugar) e, também é possível interpretá-lo como verbo com papel instrumental, que acompanha o verbo principal e que possibilita que a locução verbal seja substituída por uma forma sintética (fui comprar = comprei/ vai começar = começará).

Quanto à transitividade verbal, Neves (2005, p. 25) destaca as seguintes classes principais de verbos: (i) verbos cujo objeto sofre mudança no seu estado; (ii) verbos cujo objeto não é um paciente afetado; (iii) verbos que possuem um complemento não-preposicionado (objeto direto) e um complemento preposicionado, (iv) verbos que têm complementos oracionais e (v) verbos-suporte. Ao tratar desta última classe, utiliza como exemplos as construções "dar um grito", "dar um riso", "dar um beijinho", "dar um chute" e "dar uma investida", afirmando que os verbos-suporte são "verbos de significado bastante esvaziado que formam, com seu complemento (objeto 
direto), um significado global, geralmente correspondente ao que tem um outro verbo na língua" (Mateus et al., p. 53). Não se compreende, no entanto, o motivo pelo qual considera como verbos plenos (principais) os sublinhados em "Eu não lhe dera a cacetada pelas costas" e "(...) Matatu deu-lhe uma facada no peito", já que o verbo "dar"está esvaziado semanticamente (perdeu a noção primária de transferência de algo concreto), age sobre o elemento nominal, conferindo-Ihe função predicante e com ele formando um todo significativo, ou seja, possui as características de verbo-suporte.

Mateus et al. (2003) classificam os verbos quanto ao papel que desempenham, baseando-se nas propriedades de seleção categorial de cada item lexical verbal. Entre as categorias verbais descritas, enfocam os verbos plenos e verbos leves (ou verbos-suporte).

Ao tratar dos verbos plenos, as autoras utilizam um aspecto semântico, denominando-os núcleos semânticos da oração, ou seja, "núcleos lexicais plenos, caracterizados por determinadas propriedades de seleção semântica (número de argumentos e respectivo papel temático) e sintática (categoria de cada argumento e relação gramatical que assume na oração)" (Ibidem, p. 296). llustram essa categoria com o seguinte enunciado com verbo "dar": "O João deu um livro ao Pedro". As autoras procuram distinguir de forma clara os verbos "plenos" dos verbos "leves". Afirmam que estes "sofrem um processo de esvaziamento lexical - gramaticalização - que permite que o centro semântico da frase se desloque para expressão nominal" (Mateus et ali., p. 312) que o acompanha. Acrescentam, ainda, que a grelha argumental que o verbo tem como verbo pleno permanece, o que mostra que o esvaziamento lexical não é completo. As autoras somente tratam de construções com verbo leve "dar" que apresentam uma situação eventiva do tipo transferencial, desconsiderando construções como "dar pulos" e "dar baixa", que apresentam valor genérico de atividade, sem reter valor de transferência.

Esteves (2008) desenvolveu um estudo sobre construções com dar+SN. Com base em corpora do Português Brasileiro e Português Europeu dos séculos $X X$ e $X X I$, a autora verificou que, por participar de construções de comportamento sintático-semântico regular, o verbo "dar" pode ser 
funcionalmente categorizado em uma cadeia de gramaticalização que abarca as seguintes categorias: verbo predicador pleno (pleno ou principal), verbo predicador não-pleno, verbo predicador a verbo-suporte, e verbo-suporte. Como verbo predicador (pleno ou não pleno), "dar", além de possuir comportamento lexical na estruturação do enunciado, é o único responsável pela atribuição de papel temático ao(s) seu(s) argumentos: "Acabei dando"a sacola à ele, depois ele mandou eu soltar do ônibus, e ele soltou um ponto depois." (PB escrito, narrativa de experiência pessoal). Como verbo-suporte, "dar"apresenta uma extensão de sentido/uso de um verbo predicador e associa-se a um elemento não-verbal, partilhando com este a função de projetar argumentos e atribuir-lhes papel temático: "Ontem à noite deu banho(banhou) no miúdo." (PE, oral). Ao manifestar traços da forma fonte e da forma alvo, o verbo "dar"pertence a uma categoria intermediária: a categoria verbo predicador a verbo- suporte, que contempla os casos em que pode ser interpretado como predicador, o núcleo sintático-semântico da predicação, e como verbo-suporte, forma semi-gramatical que compartilha a função predicante com o SN que, sob atuação daquele, se torna o núcleo semântico do predicador complexo que formam ("dar respostas"= "responder" ou "fornecer respostas"). Esteves (2008), também, investigou a alternância (apenas em corpora do PB) entre predicadores complexos ("dar amor") e verbos plenos ("amar"). Os resultados dessa pesquisa revelam a maior produtividade destes do que daqueles em relação à distribuição geral dos dados. No entanto, a análise probabilística permitiu constatar que a tendência ao emprego de predicadores complexos ocorre, principalmente, quando o falante deseja marcar alguma nuance de sentido especial ("dar um beijinho" em vez de "beijar"; "dar muita tristeza" em vez de "entristecer") e quando a perífrase apresenta menor extensão silábica ("dar parabéns" - 4 sílabas) do que o verbo pleno ("parabenizar" - 5 sílabas).

\subsection{Atividades em livros/textos didáticos e algumas orientações para a abordagem de perífrases verbais e verbo-nominais em aulas de Português}


Os livros didáticos, em sua grande maioria, abordam o tema sobre verbos auxiliares na seção em que se apresentam as classificações de verbos (regular, irregular, anômalo, defectivo e abundante). Nesse tipo de encaminhamento, a única preocupação é a de mostrar que há tempos compostos formados por um verbo auxiliar e um principal. Assim sendo, os verbos auxiliares abordados somente são "ter", "haver", "ser" e "estar".

Outra ausência nos livros didáticos é a de um tratamento sintático dos verbos auxiliares. Esse tipo de verbo tem comportamento sintático-semântico que pode servir de parâmetro de diferenciação dos verbos plenos/principais. Não se comenta, por exemplo, que verbos auxiliares prototípicos são incapazes de selecionar argumento e possuem informação semântica restrita somente apresentam sinalizações linguísticas (tempo, modo, número, pessoa etc.). $O$ que se percebe, nessas obras escolares, é um reducionismo no tratamento dos auxiliares que se traduz pela idéia de que tais elementos linguísticos servem somente para formar tempos compostos e possuem quatro representantes ("ter", "haver", "ser" e "estar").

O tratamento de verbos auxiliares não se restringe a uma abordagem morfológica. llustrar casos de polissemia com esses elementos linguísticos pode ser um bom começo para anular o reducionismo comentado. Verbos como "ir", "andar" e "passar", por exemplo, podem tanto funcionar como verbo pleno, como auxiliar.

(1) Os noivos foram a Paris.

(2) Amanhã, vai chover forte.

(3) O professor recomendou que eu andasse trinta minutos todos os dias.

(4) Andam falando mal de você para os alunos.

(5) Civilizações antigas passaram da Ásia para a América pelo norte

do que hoje é o Alasca.

(6) As aulas de Português passaram a ser no segundo andar.

Dependendo do desenvolvimento de uma turma, é relevante mostrar aos alunos que certos verbos, assim como outros inúmeros itens linguísticos, passam por mudanças que podem afetar seu significado e sua função na frase (cf. processo de gramaticalização). Esse processo afetou, por exemplo, "ir", 
"andar" e "passar", visto que seus significados plenos de movimento espacial foram alterados, assim como suas funções sintáticas, de verbo predicador a verbo auxiliar.

Assim como ocorre com a abordagem de locuções verbais, cremos que ainda há certos equívocos de natureza teórica e prática no tratamento de construções com verbos-suporte em materiais didáticos.

Em Carneiro (2001), em uma das atividades que aborda diferentes empregos de "dar", há a seguinte instrução: "Substitua o verbo 'dar', nas frases a seguir, por outro verbo de sentido equivalente.". São apresentadas dez frases que não estão inseridas em algum contexto interacional. Acredita-se que uma atividade como essa poderia levar em conta o tema da adequação do emprego de termos em diferentes contextos situacionais, explorando a polifuncionalidade do verbo "dar".

Em outra atividade, o autor apresenta o seguinte comando: "Substitua as expressões destacadas por um só vocábulo de valor equivalente". A maioria das expressões apresentadas na frase são construções com "dar"na categoria de verbo-suporte (dava conta, deu fim, deu as costas, entre outras). Novamente, o fato de o autor ter exposto frases desprovidas de contextos situacionais gera a dificuldade de abordar a questão da adequação linguística na construção de textos. Ao observar as respostas sugeridas pelo "livro do professor", percebemos que a expressão "deu no pé" parece pertencer a um contexto menos formal (cf. adequação à situação de comunicação sobre a qual o autor trata no mesmo capítulo) e, por isso, seria mais indicado substituí-la por "escafedeu-se", o emprego mais informal dentre as três possibilidades sugeridas, e não por "fugiu" e "escapou", cujo registro parece ser neutro (cf. adequação ao ponto de vista) e que não indicam, por si só, traço de formalidade ou de informalidade. Esse tipo de discussão somente poderia ser enfocada se diferentes contextos discursivos fossem apresentados.

Nicola (2006) é um livro didático que apresenta a definição de verbosuporte como verbos que "podem ser empregados como suporte sem conteúdo semântico, transferindo toda a carga significativa ao seu complemento". Apresenta como exemplo as construções "deu uma olhada nas vitrines da 
galeria comercial", "temos conhecimento do assunto" e "fizemos uma distinção entre titulados e não titulados". Não parece ser coerente afirmar que esses verbos transferem "toda a carga significativa ao seu complemento", visto que, no primeiro exemplo, "dar uma olhada" significa olhar rapidamente para as vitrines e é possível detectar nesta ação ainda uma transferência, mesmo que metafórica, visto que o sujeito destina ou transfere sua visão para um determinado elemento (neste caso, as vitrines). Da mesma forma, em ter conhecimento, o verbo "ter", ainda que metaforicamente, pode indicar a posse de algo bastante abstrato - o conhecimento. Vale lembrar que a permuta de "ter" por "tomar" acarretaria uma perífrase de sentido distinto, resultante da articulação da carga semântica que ainda permanece no verbo-suporte com 0 valor do nome que a este se alia. Observa-se também que o autor apenas envolve o critério semântico na definição do termo, desconsiderando o fato de que, diferentemente de um verbo predicador, o verbo-suporte partilha com 0 elemento não verbal a função de projetar argumentos.

A descrição proposta na obra destaca um aspecto positivo - os efeitos de sentido que as expressões com verbos-suporte podem apresentar. Comenta que o emprego dessas construções pode colaborar para formar enunciados informais e que o sintagma nominal de "dar uma risadinha", no contexto apresentado, "pode revelar acanhamento, ironia, menosprezo". Ademais, afirma:

Se, no lugar de "deu uma risadinha", tivéssemos a forma riu, mesmo com advérbios que a modifiquem e intensifiquem (riu ironicamente, riu de modo acanhado, etc.), não seriam possíveis as entrelinhas sutis de significação: Aqui ela não riu. (indica que não efetuou a ação de rir). (NICOLA, 2006, p. 86)

Acredita-se que o autor ainda poderia usar os exemplos "dei uma olhada", para comentar as funções ligadas ao aspecto verbal (mais momentâneo), e "fizeram uma distinção", para discutir sobre a valência (a depender do contexto, não há necessidade de detalhar o complemento "entre titulados e não titulados"). Além disso, poderiam ser contempladas expressões com verbossuporte cujo equivalente verbal não é cognato ao elemento não verbal da perífrase, tais como "dar conta do trabalho" e "dar as costas". Nessa obra, 
encontrou-se apenas um exercício em que o emprego de verbo-suporte foi considerado.

Compare os pares e comente suas sutis diferenças de significação, ênfase, aspecto.

I. Fotografaram o momento da votação de Celina Guimarães Viana.

II. Tiraram uma foto histórica do momento da votação de Celina Guimarães Viana. (NICOLA, 2006, p. 87)

Essa proposta de exercício está coerente com o que o autor enfatiza na parte teórica de seu texto - algumas funções semântico-discursivas. Será muito produtivo que os alunos exponham suas impressões acerca do emprego dos pares acima na constituição do discurso. Devem, provavelmente, perceber a versatilidade sintática da perífrase (possibilidade de inserção de elementos "uma/histórica") e a diferença de seu sentido em relação ao verbo "fotografaram". Logo, é possível que os alunos comentem, em relação ao trecho II, que um indivíduo que ouve ou lê esse trecho pode compreender que apenas uma foto foi batida (e não duas, três...), enquanto uma pessoa pode interpretar a ação presente no trecho I como "muitos fotografaram", ou seja, a ação resultou em várias fotografias.

Diferentemente dos autores citados, que dão espaço para o ensino/reflexão sobre o emprego de predicações complexas, em Martins Filho (1992), um manual de redação e estilo do jornal O Estado de São Paulo, encontram-se, entre outras, as seguintes recomendações:

Entre os chavões mais frequentes, estão as locuções e combinações invariáveis de palavras (sempre as mesmas, na mesma ordem) que também comprometem o texto. Neste caso se enquadram ainda as frases feitas que, embora originárias da literatura popular ("dar a volta por cima", por exemplo), terminam por se repetir à exaustão, produzindo o mesmo efeito do lugar comum. Eis os principais exemplos: (...) dar com burros n'água, dar mão forte a, dar o último adeus (...) (MARTINS FILHO, 1992, p. 49) (grifo nosso)

$\mathrm{Na}$ verdade, compreende-se o autor quando critica a "repetição", pois se acredita que o usuário da língua deve buscar ser coerente em seus textos e, especialmente naqueles pertencentes a gêneros formais, a repetição pode se 
tornar um aspecto negativo. No entanto, não se compartilha a idéia de evitar ou banir determinadas expressões ou verbos da língua, pois seu emprego pode estar relacionado a alguma necessidade discursiva e, portanto, adequado à situação comunicativa em que se inserem. Além disso, no caso de expressões com verbos-suporte, deve-se atentar para os seguintes aspectos: (i) o emprego do que o autor denomina frases feitas ("dar a volta por cima") não está vinculado necessariamente a textos de registro informal, de origem popular, podendo haver diversas construções (como "dar conta", "dar sorte", "dar baixa", etc.) adequadas a gêneros textuais formais e informais sem que o "bom português" seja comprometido; e (ii) o emprego de verbos polissêmicos/polifuncionais como "ter", "fazer" e "dar"com acepções distintas de, respectivamente, "possuir", "construir" e "entregar" não empobrece a língua, pois decorre de um processo natural de expansão do uso que, muitas vezes, pode favorecer o esvaziamento de significado e, consequentemente, a mudança categorial do item, de verbo predicador para verbo-suporte.

\section{Proposta de atividades}

Acreditamos que uma das formas de encaminhar a reflexão de predicações complexas compostas por ir+verbo predicador e por dar+SN é solicitar que os alunos opinem sobre sentidos dessas construções em determinados contextos discursivos. Dessa forma, os alunos poderão: (i) compreender a noção de significado básico de ambos os verbos, (ii) analisar as características sintáticas (valência quantitativa) e semânticas (acepção e tipos de argumentos selecionados) de "ir" e "dar"em cada contexto, (iii) avaliar a aplicação de testes sintático- semânticos que auxiliam a identificar o grau de auxiliaridade de "ir", e (iv) sistematizar todas as características encontradas dos dois verbos para que compreendam a atuação de "dar"como verbo predicador pleno, verbo predicador não pleno, verbo predicador a verbo- suporte e verbosuporte e o emprego de "ir"como verbo predicador pleno, verbo predicador não pleno e como verbo auxiliar. A seguir, encontram-se algumas situações comunicativas para a aplicação dessa atividade: 
a) Uma conversa entre duas amigas

Amiga 1: Você esperou seu namorado por uma hora?

Amiga 2: Claro que não! Deutrês horas quando eu me arrumei e fui à festa.

b) Um testemunho para a igreja

Eu era um rapaz muito bagunceiro... muito, saía muito... dava muito desgosto à minha mãe.

\section{c) Notícia - Jornal do Brasil}

O delegado, tendo ontem denúncia de que, na Gamboa, se achava um homem de nome José Vieira Pinto, que diziam ser o protagonista do crime de Copacabana, deu ordens, para que se descobrisse tal indivíduo.

\section{d) Entrevista com uma jornalista}

Entrevistador: Pelas andanças no mundo e conversas que você vem tendo, dá para apontar quais as tendências para o jornalismo?

Jornalista entrevistada: Mas até então, para os jornalistas, publicar era um ponto final no trabalho. Não é mais. Precisam dar conta do desencadeamento da conversa pública que é gerada a partir desta informação que eles mesmos publicaram... Isso não me parece ruim. Por que seria? Temos que repensar uma rotina jornalística, e isso é ótimo!

\section{e) Entrevista com um torcedor}

O bicho da mala preta passou lá minha filha, comprou ele!! Deu o dinheiro pra ele então... a gente não foi classificado, tá entendendo? A gente não foi pra final.

\section{f) Um adolescente de dezoito anos numa entrevista de emprego}

Eu fiz muitas tarefas de confiança. Eu costumava fazer serviços no computador como digitação, preparar as encadernações e mais. Numa vez, eu fui retirar dinheiro para o chefe no banco.

A partir dessa atividade, outros contextos discursivos podem ser apresentados para enfocar outra questão - a permuta dessas construções por predicadores simples. A pergunta central que poderia ser feita aos alunos é a seguinte: (i) com predicações dar+SN -"É possível substituir a construção com verbo "dar"por um verbo cognato ao substantivo (SN) dessa construção e, 
ainda assim, manter as características do contexto discursivo apresentado?Por quê?", e (ii) com predicações ir+verbo predicador: "É possível substituir a construção pelo verbo predicador simples correspondente com as marcas desinenciais de futuro e ainda manter as características do contexto apresentado?". Exemplos de contextos discursivos para essa atividade:

a) Depoimento escrito para o autor de um artigo científico acerca do filme que desenvolveu para área de odontologia. (texto adaptado)

Gostaria de dar-lhe parabéns pelo filme, muito didático, e muito bem desenvolvido. Gostaria de saber se poderia utilizá-lo em uma apresentação sobre PCR em tempo real, a ser ministrada Fiocruz, em outubro. Caso seja possível, gostaria de saber como fazer para salvar a apresentação. Grata. (Mestranda-Ciência de Alimentos Instituto de na Química/ UFRJ)

b) Notícias (site: http://ego.globo.com/Gente/Noticias/0,AS0-9798,00.html - Acesso em abril de 2008)

Conheça as celebridades que só querem saber de trocar selinhos. Rodrigo Scarpa, o repórter Vesgo, não perde uma oportunidade de tentar dar um beijinhoem seus entrevistados (...) O que parecia ser apenas uma moda virou rotina entre as celebridades. O caso mais recente aconteceu no aniversário de Mauricio Mattar e no show de Preta. Os dois tascaram beijos em seus convidados.

c) Manchete de uma notícia

Vamos Flusão! Vamos Ganhar!

(site:http://www.globoonliners.com.br/icox.php?mdl= mensagem\& $\mathrm{op}=\mathrm{ver} \& \mathrm{idcom}=8 \& \mathrm{id}=765$ - Acesso em maio de 2008).

d) Um informante contando sua infância para um entrevistador

Isso. E eu passei a morar com a minha avó e com o meu pai. Porque meu pai ia trabalhare me deixava com a minha avó... e aí chegava de noite, ele me ("pegava”). Pegava eu- Pegava eu e meu irmão. (PEUL - Amostra Censo).

\section{Considerações finais}

Este trabalho buscou propor uma reflexão acerca do uso e da abordagem, no ensino de morfossintaxe, de perífrases verbais e verbo-nominais. Foi 
objetivo, também, sugerir encaminhamentos possíveis para um tratamento mais coerente e sintonizado às orientações do Parâmetros Curriculares Nacionais, no que diz respeito ao enfoque dos gêneros textuais.

Primeiramente, descrevemos a proposta das gramáticas tradicionais, dos textos cuja intenção é a de descrever os fatos da língua e dos livros e materiais didáticos. Percebemos que as gramáticas tradicionais não mencionam os verbos que passam a se comportar como auxiliares após sofrerem um processo de mudança. É claro que não estamos advogando a favor do ensino de "gramaticalização", mas consideramos bastante válida a ideia de submeter os alunos a esses processos, mostrando, por meio de exemplos do português, a flutuação categorial que ocorre entre as classes de palavras.

Os trabalhos descritivos, de um modo geral, tratam do fenômeno da auxilaridade de maneira mais sistemática. Mateus et al. (2003) e Neves (2000), por exemplo, focalizam o assunto com base em critérios que separam, em vários graus, verbos predicadores de verbos auxiliares. Quanto às construções com verbos-suporte, Neves (2000) descreve tais categorias em função de um continuum, no qual se percebem contextos em que os verbos vão ter mais comportamento de suporte e em outros, mais comportamento de predicador.

As atividades aqui sugeridas, portanto, como ilustração de possibilidades de trabalho com predicações complexas (locuções verbais ou expressões verbo-nominais) podem (e devem) ser alvos de reelaboração, levando-se em conta, entre outros aspectos, a seleção de gêneros textuais condizentes com os interesses e com as necessidades dos alunos.

\section{Referências bibliográficas}

BRASIL. Ministério da Educação. Secretaria da Educação Fundamental. Parâmetros Curriculares Nacionais: $3^{\circ}$ e $4^{\circ}$ ciclos: Língua Portuguesa. Brasília: MEC/SEF, 1998.

BECHARA, Evanildo. Moderna gramática portuguesa. 37. ed. ver. ampl. Rio de Janeiro: Lucerna, 1999. 
CARNEIRO, Agostinho Dias. Redação em construção. 2. ed. ver. e ampl. São Paulo: Moderna, 2001, p. 160-182.

CUNHA, Celso; Cintra, Lindley. Nova gramática do português contemporâneo. 3. ed. Rio de Janeiro: Nova Fronteira, 2001.

ESTEVES, Giselle Aparecida Toledo. Construções com DAR + Sintagma Nominal: a gramaticalização desse verbo e a alternância entre perífrases verbo-nominais e predicadores simples. Dissertação (Mestrado em Letras Vernáculas) - Faculdade de Letras, Universidade Federal do Rio de Janeiro, Rio de Janeiro, 2008.

FURTADO DA CUNHA, Maria Angélica; OLIVEIRA, Mariangela Rios de; MARTELOTTA, Mário Eduardo (orgs.). Linguística funcional: teoria e prática. Rio de Janeiro: DP\&A, 2003.

HEINE, Bernd; CLAUDI, Ulrike; HÜNNEMEYER, Friederike. Grammaticalization. A Conceptual framework. Chicago: The University of Chicago Press, 1991.

HOPPER, Paul J. "On some principles of grammaticization". In: TRAUGOTT, E.C. e HEINE, B (eds.). Approaches to grammaticalization, v: I. Philadelphia, Jonh Benjamins Company, 1991, p. 16-35.

MACHADO VIEIRA, Marcia dos S. Sintaxe e semântica de predicações com verbo fazer. Tese (Doutorado em Letras Vernáculas) - Faculdade de Letras, Universidade Federal do Rio de Janeiro, Rio de Janeiro, 2001.

- "Perífrases verbais: o tratamento da auxiliaridade". In: VIEIRA, S.; BRANDÃO, S. (Orgs.). Morfossintaxe e ensino de Português: reflexões e propostas. Rio de Janeiro: In-Fólio, 2004, p. 65-96.

MARTINS FILHO, Eduardo Lopes. Manual de redação e estilo. 2. ed. São Paulo: Maltese, 1992.

MATEUS, Maria Helena Mira et al. Gramática da língua portuguesa. 5. ed. Lisboa: Caminho, 2003.

MENDONÇA, Márcia. "Análise linguística no ensino médio: um novo olhar, um novo objeto". In: MENDONÇA, M.; BUNZEN, Clecio (Orgs). Português no ensino médio e formação do professor. São Paulo: Parábola, 2006.

NEVES, Maria Helena de Moura. Gramática de usos do português. São Paulo: UNESP, 2000, p. 53-61.

NICOLA, José de. Língua, literatura e produção de texto. 1. ed, v. 2, São Paulo: Scipione, 2006. 
OLIVEIRA, M. R.; CEZARIO, Maria Maura. PCN à luz do funcionalismo linguístico. Disponível em: http://rle.ucpel.tche.br/php/edicoes/v10n1/03Maria.pdf Acesso em janeiro de 2008.

OLIVEIRA, Vinicius Maciel de. Caracterização da polifuncionalidade morfossintática, semântica e discursiva do verbo ir. Dissertação (Mestrado em Letras Vernáculas) - Faculdade de Letras, Universidade Federal do Rio de Janeiro, Rio de Janeiro, 2009.

ROCHA LIMA, Carlos Henrique da. Gramática normativa da língua portuguesa. 31. ed. Rio de Janeiro: José Olympio, 1992. 